\title{
A violência e a estrutura judiciária brasileira
}

\author{
HÉLIO BICUDO
}

$S$ ABEMOS QUE A questão da violência deve ser encarada e enfrentada não apenas do ponto de vista do Poder Judiciário. Diga-se, antes de mais, não ser só o Poder Judiciário que deve ser responsabilizado pelo volume de violência que vemos ascendendo a cada passo no Brasil e no mundo. Em primeiro lugar, temos leis penais velhas, draconianas, dirigidas em especial para as classes populares. As punições não aparecem em crimes de corrupção e estes, na verdade, constituem uma outra face da problemática; poderíamos até dizer que constituem a face mais importante da violência, porque a primeira é a face miúda, é a face do crime popular, dos furtos, dos assaltos, dos homicídios, enfim, de todos os crimes que estão tipificados na Lei Penal e são praticados pelas classes populares e violentamente reprimidos pela polícia ou pela justiça e, depois, pela prisão.

Costumo dizer que a questão da segurança pública não pode ser enfrentada segundo cada órgão do Estado, ou seja, segundo a Polícia, o Poder Judiciário, o Ministério Público, os próprios advogados e, depois, a prisão. Penso que essas instâncias têm que ser vistas de maneira mais unificada e não como departamentos estanques: aqui é a polícia, aqui é a justiça e aqui é a prisão. Acho que as três devem ser vistas de maneira mais global, porque uma depende da outra.

Se temos leis penais realmente aptas a impedir ou punir a violência, se temos uma polícia que realmente seja preventiva e não apenas repressiva, diminuem, evidentemente, as tarefas do Poder Judiciário no que respeita à violência.

Hoje encontramo-nos diante de uma violência reprimida, por uma polícia incapaz, ineficiente, corrupta e por um Poder Judiciário que se fecha cada vez mais dentro de si próprio.

Dentro desse contexto, o Poder Judiciário brasileiro é uma corporação e atua como tal. Os juízes que buscam alguma autonomia, alguma independência no exercício de suas atribuições, são rapidamente sufocados. E esse sufoco avança a cada passo; o autoritarismo hoje no Poder Judiciário é um de seus atributos maiores. E esse autoritarismo é, em certa medida, responsável pela manutenção da violência.

Quando se fala em reforma da estrutura do Poder Judiciário, a quase unanimidade dos juízes acha que precisa haver reforma. O próprio presidente do Supremo Tribunal Federal, o ministro Sepúlveda Pertence, diz que ela é necessária. Mas é de se perguntar qual a reforma que ele entende que deva ser feita. Será a reforma que ele pensa ou a reforma que é necessária? Se o ministro Sepúlveda Pertence 
pensasse realmente numa reforma profunda do Poder Judiciário, não estaria promovendo a construção de um novo anexo ao Supremo Tribunal Federal, maior do que as duas unidades já existentes - o próprio edifício primitivo do Supremo e o seu primeiro anexo -, obra que se está construindo em Brasília ao custo de R $\$ 48$ milhões. Então, quando se diz que os juízes do Supremo Tribunal Federal julgam de 1.500 a 2.000 causas por ano, essa será toda a verdade? Se examinarmos os julgamentos do Supremo Tribunal Federal nas seções plenárias nas quais os ministros dão os seus votos, nunca chegaremos a esse número, que seria (dê-se de barato) de cerca de 1.500 votos por juiz que, multiplicados por 11 , dariam quase 16 mil votos em um ano! A grande tarefa é, na verdade, feita por assessores e apenas assinada pelos juízes. E quando se fala em recolocar o Supremo Tribunal Federal naquilo que o Supremo Tribunal Federal, pelo menos na minha visão, deve ser - a corte constitucional do Brasil - os juízes se rebelam e querem continuar com a competência que têm hoje, porque à medida em que a sua competência se avoluma, maior o seu poder. E os juízes do Supremo Tribunal Federal não querem perder esse poder. Então, a questão de um novo Poder Judiciário começa a sofrer o impacto da própria cúpula da magistratura brasileira, em especial do Supremo Tribunal Federal.

Tenho ouvido algumas vezes, numa comissão especial que se instalou na Câmara dos Deputados para examinar a questão da reforma do Poder Judiciário, manifestações do ministro Sepúlveda Pertence, manifestações inteiramente corporativas.

Através dessa inverdade - a afirmação de que um juiz do Supremo Tribunal Federal dá aproximadamente 1.500 sentenças por ano - vem a questão da súmula vinculante. A súmula vinculante permitiria que esse número exagerado de decisões por juiz do Supremo Tribunal Federal decrescesse de 1.500 para pouco mais de 600 por ano. Como as questões podem ser decididas na base de uma cristalização obrigatória da jurisprudência? O que é jurisprudência? A jurisprudência é constituída de uma série de decisões que levam a determinada meta. Ela serve de orientação para os juízes, mas não é determinante da decisão que possa tomar.

Agora, se nós tirarmos do juiz essa possibilidade, estamos tirando dele a sua própria criatividade. Quer dizer: o juiz, para interpretar a lei, não iria mais usar os seus conhecimentos, a sua vivência, a sua experiência enquanto pessoa. Ele irá usar a súmula 125 do Supremo Tribunal Federal e ponto final. Nesse caso, estaremos impedindo até mesmo o progresso intelectual da magistratura brasileira, sobrepondo ao dinamismo da jurisprudência o interesse do governo ou do próprio Supremo Tribunal Federal. Tal perspectiva me faz lembrar, como já assinalei, a reforma proposta durante a ditadura militar nos seus pontos principais: a súmula vinculante e o conselho nacional da magistratura.

Eu não entendo que semelhante atitude leve ao aperfeiçoamento do Poder Judiciário. $O$ aperfeiçoamento do Poder Judiciário virá na medida em que esse poder se democratizar. E esse poder não é democrático, é autocrático, na sua organização e na sua maneira de ser. As questões internas do Poder Judiciário são decididas dentro do Poder Judiciário. A sociedade civil não tem acesso a essas decisões. 
Quando se diz, por exemplo, que o Tribunal de Justiça de São Paulo afastou vários juízes, esses juízes não foram, entretanto, submetidos ao devido processo legal, mas apenas postos em disponibilidade, com os vencimentos dos cargos que ocupavam na ocasião do afastamento. Na verdade o Poder Judiciário se mantém, ele próprio, dentro da sua própria estrutura e năo se abre. Lembro-me de que, certa feita, em conversa com um dos presidentes do Tribunal de Justiça de São Paulo, este queixava-se da falta de juízes. Isso ocorreu há quatro ou cinco anos atrás. Ele me dizia da necessidade, em São Paulo, de mais de 300 juízes; havia então um concurso em andamento, o qual não iria recrutar mais do que 10 juízes. Em resposta, indaguei por que não se abria esse concurso, por que não se regionalizava o processo de escolha.

Ora, um concurso para juiz ou promotor de justiça leva normalmente scis meses, pouco mais ou menos. Dessa forma, como pode se permitir que advogados, muitas vezes excelentes, que militam no estado em cidades como Presidente Prudente, Rio Preto, Ribeirão Preto, Bauru, entre outras, venham para São Paulo e se ponham à disposição de um concurso, interrompendo suas atividades profissionais para disputar um cargo de juiz? Daí a pergunta: por que não se descentraliza esse concurso? Se em cada concurso serão recrutados 10 ou 20, se simultaneamente fossem realizados cinco concursos, dividindo-se São Paulo em cinco regiões, poder-se-ia, assim, recrutar os juízes imprescindíveis à tarefa de distribuição da Justiça no estado.

Mas como deslocar, indagava o meu amigo, um desembargador para fazer parte de uma banca em Rio Preto? Isso quer dizer que essa estrutura não funciona porque a justiça de São Paulo (estado com 35 milhões de habitantes) tem um único Tribunal de Justiça no centro da cidade e o recrutamento de seus juízes se faz de maneira centralizada. São evidentes, portanto, as dificuldades para a distribuição da justiça em todo o estado, pois mesmo quando se desce da segunda para a primeira instância vamos encontrar a mesma centralização. Quando se vota uma lei para o julgamento das causas de menor potencial ofensivo ou de menor conteúdo econômico, por exemplo, os fóruns são centralizados. Destarte, as causas de pequeno valor são decididas em fóruns centrais ou regionais. A justiça não vai ao povo, e essa é uma briga que eu venho desenvolvendo há mais de 30 anos.

Recordo-me que, de 1959 a 1962, quando governou São Paulo o professor Carvalho Pinto, nós conseguimos convencer o Poder Judiciário paulista, dentro do plano de ação do governo, da necessidade de descentralização da justiça no estado. Na ocasião, conseguimos sensibilizar os desembargadores no sentido de que era uma necessidade, já naquele tempo (1959-60), a descentralização da justiça de primeira instância. Em outras palavras, a criação do juiz de bairro, do juiz da periferia. Tem-se, nesse enfoque, o acesso do povo à justiça com maiores facilidades; as pessoas passam a conhecer o juiz e este aos seus jurisdicionados. Hoje o juiz não conhece ninguém, não só porque ele está nos fóruns centrais ou regionais, mas também porque existe na nossa organização judiciária uma compartimentação de funções no que diz respeito à distribuição da Justiça Criminal. Temos o inquérito policial e o processo judicial. Mas é no inquérito policial 
que se fabrica a matéria-prima para que a justiça funcione. Como, então, dissociar esse inquérito policial do julgamento pelo juiz?

$\mathrm{Na}$ grande maioria dos casos, os juízes julgam papéis, não julgam pessoas. $\mathrm{O}$ que vem no inquérito policial é sacramentado pelo promotor público e aceito pelo juiz. Então, na verdade, essa Justiça Criminal no Brasil é mais uma fantasia, uma ilusão, do que realmente uma Justiça Criminal e nós estamos vendo isso a cada passo.

Hoje, com o propósito sério de uma fiscalização da polícia pelo Ministério Público (o que naturalmente está criando seríssimos problemas para o próprio Ministério Público), algumas dessas violências policiais começam a ser desvendadas. Está aí, para ilustrar o que estamos afirmando, o caso recente do Bar Bodega. Mas não cabe apenas essa fiscalização dos atos da polícia civil; por que não estender tal fiscalização também aos inquéritos policiais militares?

Ou o Ministério Público faz uma fiscalização geral e assume as responsabilidades relativas ao ponto inicial no qual a Justiça Penal se fundamenta, ou na verdade nós vamos continuar tendo uma justiça penal dirigida apenas às classes populares.

A questão da intervenção do Ministério Público dá maior importância ao inquérito policial comum e é também fundamental no inquérito policial militar, que é uma peça fabricada nas auditorias militares e serve de fundamento não mais às condenações daqueles que compõem as classes populares mas à impunidade daqueles que compõem o aparelho policial.

Tais inquéritos realmente são dirigidos nesse sentido. Basta ter acesso a esses procedimentos para verificar-se que, ou nós corrigimos aquilo que é a mola propulsora da Justiça Penal, ou nunca vamos ter uma Justiça Penal realmente condizente com as necessidades do conjunto da população.

A nossa polícia é repressiva, não preventiva. Se fosse preventiva, o número de crimes seria menor. Nos EUA, em Nova Iorque, com a adoção de novos métodos policiais, a criminalidade decresceu e, em conseqüência, a impunidade. Por que? Porque o policial nos EUA está fazendo hoje, em Nova Iorque, o que antigamente faziam os nossos padres ao visitarem as casas dos paroquianos. A polícia em Nova Iorque está visitando as casas, está visitando as fábricas, as lojas, as escolas, para verificar onde se encontram as sementes da criminalidade e atuar em conseqüência com uma ação muito mais social do que apenas policial. Entretanto, tal procedimento só é possível se houver vontade política para fazê-lo.

Na verdade, com uma polícia militarizada, que ainda tem relações íntimas com o Exército brasileiro (porque é o Exército brasileiro que dita as normas de organização das polícias militares no seu conjunto) e que não é treinada para assumir funções de policiamento, o resultado só pode ser a violência, pois os militares das Forças Armadas são treinados para a violência. Um policial, porém, não pode ser treinado para praticar violência, pois ele deve ser o ator da segurança, o ator da paz na sociedade, na comunidade. Entretanto ele não é esse ator, é o ator da violência, exatamente pela estrutura hoje existente na polícia brasileira. 
Mas quando se põe o dedo nessa questão, se põe o dedo naquilo que as forças armadas ainda entendem essencial para sua existência, que é o domínio da sociedade civil. Temos muitas dúvidas em afirmar que hoje as polícias militares se subordinem aos governadores, pois até o seu efetivo precisa ser aprovado pelo Exército, ou seja, pela Inspetoria Geral das Polícias Militares, que é comandada por um general de Brigada.

Veja-se o caso de São Paulo: o estado tem uma polícia militar que deveria realizar o policiamento preventivo, ostensivo, do qual detém, constitucionalmente, o monopólio. À polícia civil não cabe o policiamento ostensivo mas, teria, por outro lado, o monopólio da investigação criminal, segundo a Constituição. No entanto, a Polícia Militar paulista tem um efetivo de pouco mais de 70 mil homens para um estado de 35 milhões de habitantes. Essa polícia não trabalha 24 horas por dia: o policial tem turnos de trabalho de seis a oito horas, o que nos leva a dividir esse número do efetivo quase que por quatro. Além disso, temos a polícia de trânsito, que não faz policiamento ostensivo: pode-se cometer um crime na presença de um policial de trânsito que ele provavelmente não toma qualquer providência porque essa não é sua função. Temos, ainda, as polícias dos presídios. Acrescente-se o pessoal burocrático, os policiais que exercem funções administrativas, além dos que estão em gozo de férias ou licença ou deslocados para outros órgãos do estado. Verifica-se, então, que o número de policiais em atividade não é adequado para o policiamento.

Ora, esse efetivo, nos moldes em que a polícia militar existe, deve ser aumentado ou não? Isso deverá ser feito em favor da população ou em seu detrimento? São perguntas que ficam sem resposta. Portanto, é necessário que se faça uma reforma da estrutura policial. Sem essa reforma eu não aconselharia o aumento do efetivo da PM. Ou nós modificamos essa estrutura ou então ficaremos como estamos, o que talvez seja mais confortável para a segurança das pessoas.

E a par disso, acrescente-se a resistência dos juízes em estabelecer uma interação com a população para a qual devem julgar. Essa interação aconteceu no passado distante, quando existiam pequenas comunidades no interior dos estados, as quais tinham juízes, promotores e advogados exercendo suas funções localmente. Essa interação não mais existe. Um juiz ou um membro do Ministério Público ou um delegado de polícia convive muito pouco tempo com a comunidade a que deve servir. Não há conhecimento mútuo entre partes; promotor, juiz, delegado de polícia são pessoas estranhas, ninguém sabe quem é quem. Se ninguém sabe quem é quem, como se poderá exercer o poder de julgar?

Quando eu vejo, por exemplo, a guerra que existe em São Paulo - menos evidente porque ocorre mais na periferia -, e no Rio de Janeiro - mais evidente porque a periferia está dentro da cidade -, eu me pergunto por que as autoridades não vão à periferia. Só vão à periferia nas blitz - operações violentas da polícia. Por que não temos, por exemplo, em São Mateus, na Zona Leste de São Paulo, um juiz de direito, um promotor público, um delegado de polícia morando lá, em vez de residir nos Jardins? Deveriam dar o expediente lá, morando lá, porque essa regra de o juiz morar na sua circunscrição judiciária é regra constitucional não- obedecida. 
Observe-se, por exemplo, um grande centro como Ribeirão Preto. A grande maioria dos juízes das cidades vizinhas mora em Ribeirão Preto. $\mathrm{O}$ mesmo se repete no entorno das grandes cidades. Não moram mais nas suas comarcas e passam por elas quase como gato sobre brasas. Como é que vão conhecer as pessoas que se submetem à sua jurisdição em tempo tão exíguo?

Quando, pelos idos de 1948, eu exercia a promotoria pública em Igarapava, uma pequena cidade de talvez 15 mil habitantes, depois de algum tempo conhecia todo mundo, sabia quem era o Antônio, o José, a Maria, a Benedita e quando havia uma infração sabia por que essa infração ocorrera e quais as medidas que poderiam ser tomadas. Evidentemente, se fosse o caso de um delito, as pessoas seriam condenadas e, na cadeia, essas pessoas podiam comunicar-se livremente com o juiz, com o promotor, com as famílias. Freqüentemente um detento solicitava: "olha, fulano de tal está com a filha doente e ele precisaria passar três dias com a família". E o detento saía e retornava no dia estipulado. Hoje isso não acontece mais.

O que acontece hoje? Os juízes não querem ter estabilidade nos seus distritos judiciários. Tendo em vista tal fato, uma das sugestões que fiz na proposta de reforma do Poder Judiciário foi exatamente a de acabarmos com a promoção horizontal dos juízes e fazermos a promoção vertical.

\section{O que é a promoção horizontal e o que é a promoção vertical?}

A promoção horizontal é essa que existe, o Poder Judiciário de primeira instância é dividido em entrâncias, primeira, segunda, terceira e quarta, ou especial, e o juiz ou o promotor passam de uma entrância para outra por merecimento ou por antigüidade em muito pouco tempo. Um juiz não fica mais de seis meses numa comarca. Então ele vai sendo removido ou promovido, chegando a São Paulo rapidamente. Hoje essa carreira, no interior, não dura mais do que três ou quatro anos. Daí a proposta de promoção vertical. $O$ juiz pode ser promovido ou deve ser promovido na comarca onde ele se encontra, não precisando sair dela para obter uma promoção.

Em São Paulo podemos assinalar que o ministro Costa Manso, que foi um dos juízes de maior conteúdo não só jurídico mas humano, chegou a ministro do Supremo Tribunal Federal tendo feito sua carreira na primeira instância em Mogi Mirim. Ele foi juiz da cidade antes de vir para o Tribunal de Justiça de São Paulo. Mas foi por muitos anos juiz de Mogi Mirim, cerca de 15 ou 16 anos. Ele sabia exatamente o que estava fazendo. Não era essa loucura que hoje existe para qualquer advogado, qualquer promotor que entra no fórum e vê, a cada dia, um novo juiz. Isso não é administrar justiça. Ora, a justiça precisa ir ao povo, não pode ficar como ela está, nos palácios de justiça. Aliás, é uma verdadeira mania essa de se construir palácios de justiça. Qualquer cidade quer ter o seu, e que não é palácio de justiça coisa alguma, é o lugar onde se fabricam decisões e, do ponto de vista criminal, decisões que já vêm modeladas pelo inquérito policial ou pelo inquérito policial militar.

A questão da justiça militar das PMs é uma das coisas mais absurdas que eu 
já vi na minha vida. Não existe país no mundo que tenha esse tipo de justiça e quando se procura alterar a competência dessa justiça, as resistências são enormes; elas vêm do Exeercito, vêm da corporação e vêm da sociedade civil.

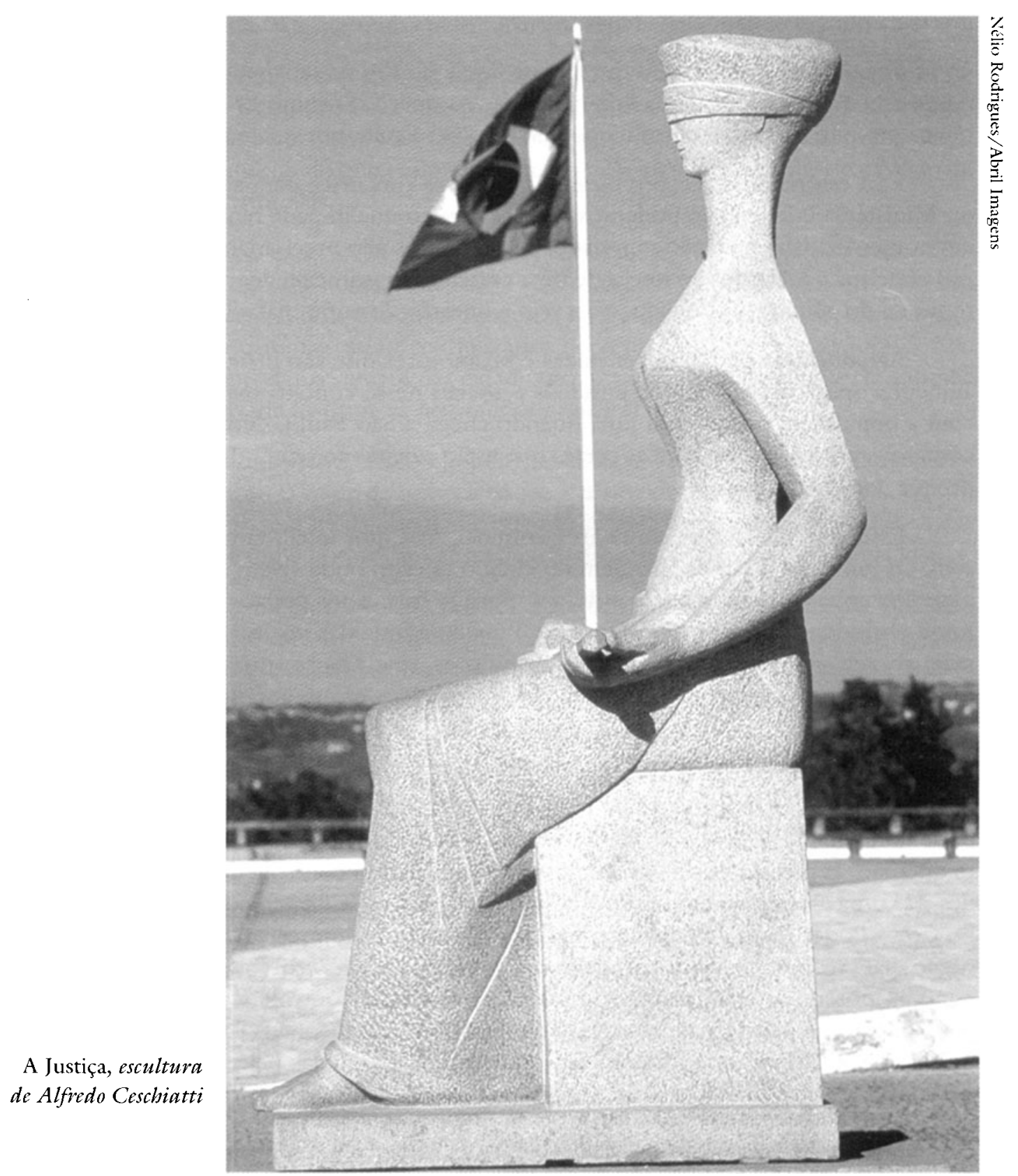

Eu já ouvi o argumento que, aliás, é muito parecido com outro, passando hoje no Senado, a respeito do crime de tortura: se os policiais tiverem certeza de que serão punidos pelas violências que cometem, eles não poderão policiar. É o mesmo argumento que está correndo no Senado na tramitação do projeto que 
tipifica o crime de tortura. Mas como, indaga-se, se não houver um pouco de violência, pode ser construída a prova criminal? Parece incrível, mas é absolutamente verdadeiro. É essa a causa da demora da aprovação desse projeto no Senado, o qual já foi apreciado na Câmara. É que o Senado está recebendo esse tipo de investida por parte da sociedade civil.

Vejamos, por exemplo, a questão da favela no Rio de Janeiro, ou da periferia de São Paulo. Eu quero o juiz na favela, eu quero o promotor na favela, eu quero um juiz e um promotor na periferia de São Paulo, por que não?

Essa estória de dizer, por exemplo, que nos concursos para a magistratura ou Ministério Público não podemos descer o nível, o que impede tenhamos juízes em número satisfatório, não tem maior sentido. Nós não precisaríamos de técnicos perfeitos e acabados ao início de uma carreira, no primeiro degrau da magistratura e do Ministério Público. Não vejo a questão de outra maneira.

Acredito que podemos ter juízes e promotores que vão progressivamente aumentar seus conhecimentos jurídicos e sociais nesse contato mais demorado com a população, porque um juiz, quando chega a São Paulo, deixa de ter esse contato; sua relação é só com as partes que estão sujeitas ao seu poder, nada mais do que isso.

Esse fato não ocorre só na área criminal, mas, por igual, também na área civil. Os juízes nada conhecem além do círculo estreito onde vivem. Eu não diria a mesma coisa dos promotores públicos, porque hoje e aos poucos a instituição foi se abrindo. Atualmente o Ministério Público é uma das instituições públicas mais abertas em decorrência de suas atribuições, que não se situam apenas no campo criminal; são atribuições que vão muito além e que abrangem extenso conteúdo social.

Hoje, por exemplo, o Ministério Público tem um instrumento poderosíssimo na luta contra a corrupção que é o inquérito civil público. Agora, todo o esquema pode funcionar se se deixar de lado a sociedade civil, a população? Evidentemente que não. É preciso que se descubram modelos para o controle dessas atividades. Há uma grande reação do Poder Judiciário quando se fala no controle externo desse Poder. Não acredito em um órgão de controle externo, porque este órgão, para realmente funcionar, deveria ser realmente externo. Nos modelos que estão aí, porém, se trata mais de um órgão interno de controle, com pequeno disfarce externo pela introdução de duas ou três pessoas de fora da corporação, as quais, por serem minoria, podem ser rapidamente cooptadas pelo conjunto da corporação.

Temos em andamento, no Congresso Nacional, um projeto de reforma do Poder Judiciário. Aliás, o projeto primitivo é de minha autoria, mas aparece inteiramente desfigurado no substitutivo de autoria do relator, sujeito às pressões originadas nas atuações que acoroçoam exatamente o corporativismo existente no Poder Judiciário.

Se nós compararmos esse substitutivo e o projeto de reforma do Poder 
Judiciário que foi feito ao tempo do presidente Ernesto Geisel, não iremos verificar muitas diferenças: aí está, por exemplo, a súmula vinculante que castra o Poder Judiciário de primeira instância e dispensa a existência do juiz, porque basta que se tenha um computador: tal caso já foi decidido, a decisão é esta e ponto final; quer dizer, as pessoas são ignoradas pelo formalismo da súmula.

Vai diminuir o trabalho do Supremo? Convenha-se, entretanto, não ser esse trabalho o que está sendo apontado pelos membros do Supremo Tribunal Federal. A súmula vinculante é muito mais um desejo do Executivo no que respeita às questões tributárias do que realmente uma solução para o problema do excesso de trabalho nos tribunais.

Repito: o excesso de trabalho nos tribunais é, realmente, decorrência da própria estrutura do Poder Judiciário. Veja-se o caso de São Paulo, que tem um tribunal de justiça, dois tribunais de alçada civil e um criminal, além da primeira instância. Os tribunais estão centralizados no centro da cidade e os juizados de primeira instância nos centros das cidades do interior. Daí a conclusão, já adotada pela legislação, de instituir-se juizados de pequenas causas.

Mas, francamente, não vejo por que se deva fixar a jurisdição tomando-se em consideração o valor de uma causa ou a maior ou menor intensidade de um crime. Quando se trata da liberdade, quando se trata de problemas de direitos das pessoas, este é um enfoque capitalista dentro da questão da distribuição da justiça.

Quando me sinto violado no meu direito, não estabeleço níveis de violação, o importante é que tive meu direito violado. Não quero ser julgado segundo determinados critérios mais ou menos flexíveis, de acordo com a intensidade da violação do direito a que me submeto. Quero a mesma dedicação no exame de uma causa de $R \$ 200$ milhões e em outro, numa causa de $R \$ 10$. Aliás, esta pode ser muito mais importante para mim do que os $\mathrm{R} \$ 200$ milhões para um grande empresário. Uma bofetada pode ser muito mais importante para mim do que um ferimento grave. Por que, nessas condições, temos de ter juízes para pequenas causas?

O que são pequenas causas afinal de contas? É um disfarce que deixa as coisas como elas são. Fala-se em pequenas causas e não se modifica a estrutura do Poder Judiciário. Penso que se nós conseguirmos descentralizar a justiça, teremos dado um passo significativo no seu aperfeiçoamento. Muitas pessoas dizem que isso é uma utopia, mas nunca alguém tentou enfrentar tal utopia para torná-la concreta: descentralizar realmente a justiça.

Quando me refiro a descentralizar a justiça, falo em descentralizar a polícia, em descentralizar o presídio, mas não essa descentralização de se criar delegacias, juizados ou presídios aqui, ali, acolá e dizer que isto é descentralização.

A descentralização da justiça é a ida do juiz ao povo. A descentralização dos presídios é o presídio localizado de acordo com as necessidades de ressocialização do condenado. Quer dizer, não podemos fazer o que se faz hoje em São Paulo e no Brasil. Num crime cometido em Santos, o réu é julgado em Santos, mas vai 
pagar a pena em Presidente Prudente. Retira-se o acusado de todo o convívio que ele possa ter dentro da sociedade, o que é um fator impeditivo da sua ressocialização, pois, quando volta, é um estranho no ninho, ninguém sabe quem é; perdeu as suas raízes; não deve nada àquela comunidade para a qual retorna.

É preciso que comecemos a enfrentar a questão de maneira global. O policial não pode estar hoje na Zona Norte, amanhã na Zona Sul, depois na Zona Leste ou na Zona Oeste. O policial tem que estar numa mesma área, com o juiz, com o promotor e com o presídio.

Se encararmos uma estrutura nessa linha, talvez possamos diminuir os índices de criminalidade e aumentar a eficiência dos julgamentos: a correspondência do julgamento com o fato, o que não existe hoje no Brasil; não existe na Justiça Comum e não existe nessa Justiça Militar que ainda resiste por causa dos lobbies, aos quais o Congresso se submete.

Por que um projeto, por exemplo, que transfere a competência da Justiça Militar para a Justiça Comum tem dificuldades em tramitar nas duas casas do Congresso? Porque a nossa sociedade pende muito mais para o lado da violência do que para o lado da justiça.

Ora, o Senado é constituído, quase todo ele ou pelo menos cerca de $50 \%$ de ex-governadores que foram íntimos das polícias militares. Vou narrar um fato, como é um fato público ele pode ser narrado. Quando o projeto que desloca a competência da Justiça Militar para a Justiça Comum estava em tramitação na Câmara, procurei um deputado que foi governador de estado e é um democrata. Perguntei-lhe: "você vai votar conosco nesse projeto para retirarmos a competência da Justiça Militar, transferindo-a para a Justiça Comum?” Ele respondeu: “ah, eu não posso fazer isso." Retruquei: “por que você não pode?” Ao que ele argumentou: "não posso porque está aí o hoje presidente do Tribunal de Justiça Militar, da Polícia Militar de São Paulo, que foi chefe da minha Casa Militar e eu não posso negar um pedido feito por ele para votar nesse sentido".

Então, são coisas desse tipo que acontecem e realmente prejudicam as modificações que se pretende fazer em toda a estrutura que aí está, envolvendo a polícia, a justiça e a prisão.

O projeto de reforma do Poder Judiciário, para que se dê acesso da população à justiça, está inteiramente desfigurado no substitutivo oferecido pelo relator da Comissão Especial que o examinou. E acontece que não posso sequer retirar o meu projeto. Se pudesse retirá-lo, o faria, porque prefiro que fique como está a ficar pior, como ficará se o substitutivo for aprovado. Mas não posso retirá-lo por motivo regimental. Porque, quando se apresenta uma emenda constitucional, cada subscritor da emenda é autor da emenda, então não se pode retirar a emenda sem a assinatura de todos os seus autores. E isso vai ser impossível, mesmo porque muitos dos signatários não tiveram seus mandatos renovados.

Vamos correr o risco de uma discussão mal feita, apenas dentro da Câmara. Muito diferente do que se pretendia, ou seja, uma discussão no nível da sociedade 
como um todo, uma discussão em São Paulo, no Rio de Janeiro, no Rio Grande do Sul, no Norte, no Nordeste, uma discussão para se aquilatar o que é o Poder Judiciário hoje no Brasil e quais as alterações que se fazem necessárias. Discutir o Poder Judiciário na universidade? Ora, não se fez nada disso. Foram ouvidos apenas os ministros do Supremo Tribunal Federal, Superior Tribunal de Justiça, Superior Tribunal Militar, os representantes da magistratura através de suas associações, e não passou disso. Estou tentando abrir um pouco mais o debate ao pedir uma comissão geral porque, como o substitutivo ainda não foi votado, evidentemente é melhor que se constitua essa comissão geral antes de sua votação; então, os próprios membros da comissão especial poderão rever posições que tenham adotado.

Qual o objetivo de uma comissão geral? Objetiva-se uma grande discussão, ainda no nível da Câmara: três dias de debates, quando serão convidadas pessoas que possam dar importante depoimento a respeito do Poder Judiciário, para se verificar a possibilidade de haver uma alteração nesse substitutivo que a própria Ordem dos Advogados profliga. Acho mesmo haver consenso de que ele serve muito mais ao corporativismo do Poder Judiciário do que às necessidades populares de acesso à justiça.

Vou me deter um pouco sobre o conselho nacional da magistratura proposto pelo substitutivo. Tal conselho, na minha visão, é inconstitucional por não podermos, dentro do pacto federativo, admitir que, no Poder Judiciário, os poderes judiciários estaduais estejam sujeitos administrativamente a um conselho nacional.

Cada Poder Judiciário, dentro do seu estado, não pode ter a sua autonomia diminuída pela existência de um conselho nacional que, ademais, vai ser mais um órgão burocrático. Na verdade, se for instalado, irá, evidentemente, enfrentar a discordância dos poderes judiciários estaduais.

E a chamada Justiça Federal? A Justiça Federal de primeira instância é elitizada porque os juízes federais, que hoje começam a ser distribuídos pelos estados, são na verdade muito poucos para atender às demandas. É uma Justiça que já nasceu impedida de funcionar como deveria, pelo volume de processos que the são submetidos.

Com a descentralização da justiça nos estados teremos maior número de juízes e, se forem distribuídos fisicamente pelas várias regiões dos estados, pelas cidades, eles poderão julgar qualquer causa, as pequenas, as médias, as grandes. Teremos, também, os tribunais regionais; por que um tribunal de justiça com mais de 100 juízes em São Paulo?

Poderemos, sem dúvida, ter pequenos tribunais de justiça nas várias regiōes; ter um tribunal em São Paulo, pequeno, que funcionaria como uma corte de cassação para harmonizar a jurisprudência dos tribunais inferiores (jurisprudência, não súmula vinculante), para orientar os juízes nas suas decisões (não para obrigar o juiz a tomar esta ou aquela decisão). Então, para que Justiça do Trabalho? Por que os juízes comuns não julgam as questões trabalhistas? Se as questões realmen- 
te de interesse de patrões e empregados já estão sendo decididas através de dissídios, resolvidos entre as partes, as questões realmente jurídicas devem ser decididas pelo juiz de direito.

Acabaríamos com essa representação classística, um absurdo que hoje não tem mais sentido algum. Ademais, fala-se ainda em juízes arbitrais. Ora, isso seria a privatização da Justiça, porque, na medida que a justiça se mostra incompetente ou impotente para decidir, vão surgindo tais soluções paralelas, mas não suficientes para a resolução do problema; nada deve ser subtraído ao exame do Poder Judiciário, pois é este o poder que realmente controla todas essas questões na sociedade, as questões administrativas, as questões do povo...

Por último, não vejo com bons olhos as chamadas escolas de magistratura, para o ingresso na carreira. Já li textos, por exemplo, como o da experiência na França, que foi uma experiência negativa, porque se se começa a formar a corporação através da escola; eu não desejo ver, no Poder Judiciário, a sua qualificação como uma corporação.

O Poder Judiciário deve estar, sobretudo, voltado ao serviço da população. Somente dessa maneira poderá se constituir em fator de repressão à violência.

Hélio Bicudo é advogado e jornalista. Foi promotor público, procurador da Justiça em São Paulo e chefe de gabinete do ministro da Fazenda Carvalho Pinto (1963). Membrofundador da Comissão Justiça e Paz de São Paulo e membro da Comissão Teotônio Vilela de Defesa dos Direitos Humanos. Deputado federal pelo PT-SP 1990-1998. Presidente do Conselho de Direitos Humanos da Câmara dos Deputados. Autor de vários livros, dentre os quais se destacam: Meu depoimento sobre o Esquadrão da Morte (Comissão de Justiça e Paz, São Paulo, 1975), Lei de segurança nacional: leitura critica (Paulinas, São Paulo, 1986), Violência: o Brasil cruel e sua maquiagem (Moderna, São Paulo, 1994). Autor do projeto que transfere para a Justiça Comum os crimes dolosos contra a vida cometidos por policiais militares.

Resumo revisto da transcrição da Conferência do Mês do IEA-USP feita pelo autor em 13 de dezembro de 1996. A Editoria manteve o estilo oral da comunicação. 